Niche modelling

Biological control and climate change

Research Article

Phone: +61468939518

\section{$\mathrm{Li}-\mathrm{H} \sin \mathrm{Wu}$}

School of BioSciences, University of Melbourne, Bio21, 30 Flemington Rd., Parkville, Vic. 3010,

Australia

Fax: +61383442279

E-mail: Lihsinwuu@gmail.com

\title{
Assessing the current and future biological control potential of Trichogramma ostriniae on its hosts Ostrinia furnacalis and Ostrinia
} nubilalis

\section{Li-Hsin Wu ${ }^{a^{*}}$, Matthew P. Hill ${ }^{b}$, Linda J. Thomson ${ }^{a}$, Ary A. Hoffmann ${ }^{a}$ \\ *Correspondence to: Li-Hsin Wu, current adress: Department of Plant Medicine,}

National Pintung University of Science and Technology, Pintung 91201, Taiwan.

E-mail:lihsinwuu@gmail.com

${ }^{\mathrm{a},}$ School of BioSciences, University of Melbourne, Bio21 Institute, 30 Flemington

Rd., Parkville, Vic. 3010, Australia

This is the author manuscript accepted for publication and has undergone full peer review but has not been through the copyediting, typesetting, pagination and proofreading process, which may lead to differences between this version and the Version of Record. Please cite this article as doi: $10.1002 / \mathrm{ps} .4841$

This article is protected by copyright. All rights reserved. 


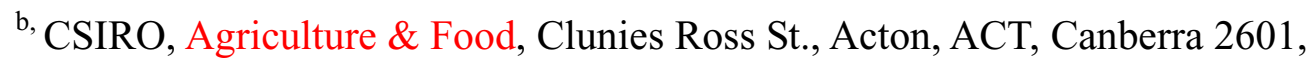

Australia

E-mail: ary@unimelb.edu.au, 1thom@unimelb.edu.au, matthill@protonmail.com

This article is protected by copyright. All rights reserved. 


\begin{abstract}
BACKGROUND: Understanding interactions between biocontrol agents and their pest hosts under climate change should assist implementation of biocontrol strategies, by identifying appropriate biocontrol agents for release or determining the optimal timing of releases. Species Distribution Models (SDMs) are applied to evaluate the distributions of Trichogramma ostriniae and its native host, Ostrinia furnacalis, in southeastern Asia, and a non-native host, Ostrinia nubilalis, in a novel range, North America, using MAXENT and CLIMEX modelling approaches.
\end{abstract}

RESULTS: Both models led to similar predictions about the expected distribution of the two species in Asia, and emphasized likely mismatches between host and natural enemy. Trichogramma ostriniae was predicted to occur in the summer corn region of China, with distribution limits linked to its sensitivity to cold, seasonality of radiation and precipitation. Modelled Ostrinia nubilalis distribution overlaps with the main corn production areas of northeastern United States and Canada; temporary/seasonal suitable habitat was predicted across southeastern states as well. Climate change scenarios are predicted to favor T. ostriniae over its hosts in northeastern China and North America.

This article is protected by copyright. All rights reserved. 
CONCLUSIONS: The modelling approaches used here proved useful for assessing environmental factors linked to an egg parasitoid and its lepidopteran hosts and identifying areas potentially suitable for inundative releases.

Keywords: biocontrol, CLIMEX, species distribution model, egg parasitoids, environmental niche model, MAXENT

This article is protected by copyright. All rights reserved. 


\section{INTRODUCTION}

Weather extremes driven by climate change are set to challenge crop production, with the potential to destabilize agricultural ecosystems and threaten local to global food security. ${ }^{1}$ To maintain sustainable pest control in crop production systems, an understanding of the extent to which climate change will affect both pests and their natural enemies (including predators and parasitoids) is needed. Climate change is expected to drive population asynchrony or coextinction of hosts, parasites and mutualists, ${ }^{2}$ highlighting that increased research attention should be focused on these important ecological relationships. There is a range of approaches for examining effects of climate change on these interactions, ${ }^{3}$ particularly for changes in the distributions and abundances of host and parasitoid. ${ }^{4}$

To make predictions of species distributions, different types of niche models are increasingly used both in biodiversity conservation and in applied ecology. ${ }^{5,6,7}$ The choice of which type of model to use is typically determined by the type data that is available for the species. ${ }^{8}$ A popular form of model is the environmental niche model 
(ENM) such as MAXENT, that aims to approximate the realized niche of species by characterising species-environment relationships using species occurrence data and environmental covariates. The realized niche inherently includes not only abiotic constraints but also other implicit factors, such as biotic interactions including competition and host-availability, as well as the ability of species to disperse through the environment. ${ }^{7}$ Correlative models are thus useful for inferring species-environment relationships and examining response of the species across its range to specific predictors to better understand distribution limits. ${ }^{9,10}$ While ENMs provide important tools to infer species-environment relationships and limits to distributions, there are issues of transferability when extrapolating these models in time and space. Species distributions have also commonly been analyzed with CLIMEX, a semi-mechanistic niche modelling tool, adopting a combination of life history parameters with abundance and distribution records. It is broadly used to investigate the interactions between biological invasions, potential response and efficiencies to climate change. ${ }^{4,10,11}$ By constructing niche models grounded on species ecophysiological traits, CLIMEX avoids some issues of extrapolation or transferability across regions and future climate change scenarios. ${ }^{10}$ CLIMEX 
determines an ecoclimatic index reflecting suitability of a location through a combination of growth and stress parameters. ${ }^{12}$

One area where CLIMEX models are useful is for predicting the distribution of classical biocontrol agents. CLIMEX has been used to identify American regions most climatically similar to native localities (southern Africa) of biocontrol agents, and thus efficiently narrowed the search range for natural enemies of two alien pest plants of significant invasion concern worldwide, Chromolaena odorate and Acacia nilotica spp. ${ }^{13,14}$ Further analyses of this nature should provide valuable information for classical biocontrol strategies, by identifying regions where natural enemies may become mismatched with their hosts, and by identifying periods of time when inundative releases with parasitoids and predators are likely to be effective. ${ }^{15}$

An important group of natural enemies are the Trichogramma (Hymenoptera: Trichogrammatidae) wasps, small egg parasitoids that help control a range of lepidopteran pests. Trichogramma spp. are often cultured and released in inundative biocontrol programs to successfully aid agricultural production. ${ }^{16}$ In comparison to 
other insect guilds, parasitoids are more likely to be sensitive to climate change ${ }^{17}$ and other environmental disturbances because of their position in the trophic web, and because of host specialization (e.g. host generalists responded faster with larger expansion/host shift ranges within habitats). ${ }^{18,19}$ To this end, parasitoids will not only be affected by the direct effects of climate change, but also by indirect effects mediated through changes in host population dynamics. ${ }^{17,20}$

The Asian corn borer (ACB), Ostrinia furnacalis Guenée (1854), is a serious pest of corn and causes more than 9 million tons of yield loss per year. ${ }^{21}$ The geographic range of ACB extends from eastern and southeastern Asia, through to western Pacific islands. ${ }^{22}$ The endemic egg parasitoid, Trichogramma ostriniae Pang \& Chen (1974), is the predominant species parasitizing $\mathrm{ACB}$ across the native range, which consists of most corn cropping regions of southeastern Asia. ${ }^{21,23}$ In China, Trichogramma biocontrol for ACB has been conducted since the early 1950s; today nearly four million hectares of cornfields are treated with $T$. ostriniae and other Trichogramma species across southeastern Asia annually. ${ }^{21}$ Surveys of both T. ostriniae and ACB in the native range provide an opportunity to model the current distribution and 
investigate potential distributions of the host and this parasitoid under climate change scenarios across southeastern Asia.

Because of its success in controlling ACB in China, T. ostriniae has been introduced to control the closely related European corn borer (ECB) Ostrinia nubilalis (Hübner 1917) in northeastern USA (New York, Massachusetts, Delaware and other locations) and Canada (southern Quebec) since the early 1990s. ${ }^{24,25,26}$ The ECB is endemic to Europe and western Asia and was introduced to northwestern America in the early $19^{\text {th }}$ century. Early inoculative releases of $T$. ostriniae showed promising results, with up to $80 \%$ of parasitism achieved in cornfields in this region. ${ }^{27}$ Inoculative releases are currently available as an option to help control European corn borer in sweet corn in New York, Kentucky and other States in northeastern US. ${ }^{28}$ Given the status of these important lepidopteran pests and the active Trichogramma biocontrol programs in place, these data provide a unique opportunity to test projections of niche models within and between continents, and assess the future effectiveness of biocontrol under climate change scenarios.

This article is protected by copyright. All rights reserved. 
In this current study we employ niche modelling to determine climatic factors associated with two lepidopteran host species and the biocontrol parasitoid, and examine potential changes in their distributions due to climate change. The specific aims of the current study are: (1) to analyze and compare species-environment relationships and niche overlap of $T$. ostriniae and its host moth ACB across their native distribution in Asia; (2) to better understand the climate suitability for $T$. ostriniae in North America for control of ECB; and (3) to examine how host-parasitoid relationships of $\mathrm{ACB}$ in Asia and ECB in North America may be altered under climate change. Determining how broad-scale climate patterns may change host-parasitoid relationships should help plan future biological control programs.

\section{MATERIALS AND METHODS}

As we had data from different knowledge domains, including field observations of distribution and phenology, physiological response information, and models of diapause, we constructed different models where appropriate. 


\subsection{Distribution data}

Occurrence data were obtained from published references (see Appendix Table S1) ( $n$ $=111$ for Trichogramma ostriniae, $n=149$ for Ostrinia furnacalis (ACB)), field surveys around southwestern Taiwan in 2014 and 2015 ( $n=9$ for T. ostriniae, $n=28$ for $\mathrm{ACB}, \mathrm{Wu}$ et $a l .{ }^{23}$ and Hsieh, 2016, pers. comm.) and the Global Biodiversity Information Facility (GBIF) database ( $n=404$ unique points for O. nubilalis (ECB)) (Fig. 1). Trichogramma ostriniae is not currently used in Europe as a biological control agent for ECB. The North American distribution of T. ostriniae listed (Table S1) was not used in model training (see below) as these data were obtained from successful inundative releases in biological control programs, and it is not clear if permanent populations have established at these release points. ${ }^{29}$ Instead, these points were used to test whether the predictions from the models matched those where inundative releases have taken place. $^{29}$

\subsection{Environmental data}

We obtained environmental data from CliMond, ${ }^{30}$ which provides data formats

This article is protected by copyright. All rights reserved. 
suitable for both correlative ENMs and CLIMEX models. For ENM model construction, CliMond provides 35 bioclimatic variables describing means, seasonality and trends for temperature, precipitation, solar radiation and soil moisture. Data for CLIMEX uses the same observations, but uses daily minimum and maximum temperatures, monthly precipitation and relative humidity. We used a grid cell resolution of 10 equator.

\subsection{ENM construction}

For the construction of correlative distribution models for Trichogramma ostriniae and its host Ostrinia furnacalis (Fig. 2), we ran MAXENT (Version 3.3.3i) ${ }^{31}$ which uses the principle of maximum entropy to relate distribution records of a species to environmental variables for estimating the potential distribution of the targeted organism. ${ }^{31,32}$ MAXENT uses information on conditions in the region of interest as a basis for comparison with conditions at known presence sites, so the regions ("background") need to be defined before model construction. We first set the background for the native range to occupied bioclimatic regions from Köppen-Geiger 
classifications within (or intersecting) the borders of China, Japan, North Korea, South Korea and Taiwan, because all our data points were contributed by references published from these areas (see Figure 1). Köppen-Geiger classifications followed the rules defined in Kriticos et al. ${ }^{30}$ as applied to the 10

climatology (sourced from the WORLDCLIM and Climate Research Unit (CRU)

datasets, $\quad \mathrm{http}: / /$ worldclim.org, $\quad$ Version $\quad 1.4, \quad$ release $\quad 3^{33}$; https://crudata.uea.ac.uk/cru/data/hrg/, Version CL2.0 $0^{34}$ ). This provides a broad geographic area to account for data availability and occurrence record biases, but omits large geographic areas that are not relevant to modelling species distributions. ${ }^{35}$

To determine key variables for model inclusion, we applied Environmental Niche Factor Analysis (ENFA) ${ }^{36}$ for the two species datasets independently across their respective backgrounds using the 'adehabitat' package ${ }^{37}$ in $\mathrm{R}$ (version 3.1.1). ${ }^{38}$ Variables were ranked on marginality, which describes the difference between the total range of environmental variables and the range occupied by the species, within the accessible area. ${ }^{36}$ The top 10 variables for both species were then checked for spatial autocorrelation. We generated 10000 random points across each background, 
extracted variable information for each of the environmental predictors, and conducted pairwise Pearson correlation tests across all variables. For variables that were highly correlated $(r>0.75)$, a variable from the pair was removed based on a lower marginality score. ${ }^{39}$ By removing variables in this manner, we could reduce issues that may be caused by multicollinearity, and its bias on models projected to novel regions. ${ }^{40}$ To enforce smooth response curves, we only enabled hinge features (see Elith et al. $^{9}$; Hill \& Terblanche ${ }^{41}$ ), all other parameters were left at default. Models were then run using 10 cross-validation replicates, taking the average of all replicates for spatial predictions. The respective predictor variable sets were then examined using the jackknife feature of MAXENT together with percentage contribution to the model.

To test for any changes to model performance from possible sampling error, we also created a buffer zone of $20 \mathrm{~km}$ around each location assigned from literature records and randomly jittered locations (see Hill et $a l^{42}$ ). The resulting mapped predictions were compared through niche overlap analysis (Schoener's $D$ statistics) using the 'dismo' package ${ }^{43}$ in $\mathrm{R}$. We then performed a one-tailed $\mathrm{t}$ test to determine whether 
the actual data set produced models different to those with random error incorporated (Appendix S1).

\subsection{Environmental Space}

In addition to modelling the distributions of all species, we examined overlap in multivariate environmental conditions across the different geographic regions. We extracted predictor information for a common predictor variable set that included all important variables across the distribution of all species. We then sampled 10000 random points across the Asia and North America backgrounds and extracted the same climatic information at these points. We performed principal components analysis (PCA) for the total combined data, and plotted the first two-axes to visually examine overlap between the different species, and the background datasets $\left(\right.$ Appendix S2) ${ }^{41}$.

\subsection{CLIMEX modelling}

The CLIMEX model processes a series of weekly growth and stress indices that are combined to derive an Ecoclimatic Index (EI). The EI indicates regions that are 
unsuitable for the species to persist, compared to those that provide an ideal environment for the species. The EI scale ranges $0-100$, with 0 representing an unfavourable environment, values over 20 considered to be ideal conditions, between 10 and 20 considered suitable, and between 0.01 and 10 considered marginal, ${ }^{41}$ though interpretations of EI are species-specific to some extent. ${ }^{10}$ For ACB and $T$. ostriniae CLIMEX models, initial parameter values were provided by a template species (Colorado beetle Leptinotarsa decemlineata (Say)), as it is also an important agricultural pest inhabiting similar latitudes, and its default simulation fitted well with known distributions. For ECB, initial parameter values were acquired from previous modelling attempts ${ }^{45}$ and refined using its native European distribution. To fit the CLIMEX model for each of T. ostriniae, O. furnacalis and O. nubilalis, the species' known native distributions together with reported range descriptions were used to iteratively adjust the model until the CLIMEX simulated geographical distribution coincided with its known distribution.

Both species here undergo facultative diapause as later stage larvae to escape suboptimal cold conditions, especially at higher latitudes. Diapause in CLIMEX is 
incorporated through a relationship between photoperiod and temperature. The diapause index is an important component in determining the yearly Growth Index, and can be adjusted according to observations from trap captures and field observations for the species. Below we describe where we made parameter changes, and the rationale for each, for the three species under investigation.

\subsection{Parameters for O. furnacalis (ACB)}

\subsubsection{Temperature index}

Lower developmental threshold ranges were 6.8 to $10.4^{\circ} \mathrm{C}$ for $O$. furnacalis. ${ }^{22}$ In the current study, the minimum temperature for development (DV0) was set at $6.8^{\circ} \mathrm{C}$. The lower and upper optimum temperatures (DV1, DV2) were set at 20 and $28^{\circ} \mathrm{C}$, respectively. The upper temperature threshold was close to $33-35^{\circ} \mathrm{C}$, so the upper threshold temperature (DV3) was set at $33^{\circ} \mathrm{C}$.

\subsubsection{Moisture index}

Moisture index values limited the establishment of both species in western China and

This article is protected by copyright. All rights reserved. 
across the southeastern mountain areas. The lower soil moisture limit for development (SM0) was set to 0.15 to indicate the lowest moisture threshold points of the egg parasitoid and its lepidopteran host. This limit normally corresponds to approximately $10 \%$ of soil moisture level. The lower and upper limits for optimal growth (SM1, SM2 and SM3) were set to levels considered biologically reasonable for current distributions, or $0.35,0.80$ and 1.5 , respectively.

\subsubsection{Cold stress}

For ACB cold stress, temperature threshold (TTCS) and cold stress accumulation rate (THCS) were set to $0.5^{\circ} \mathrm{C}$ and -0.0001 week $^{-1}$. EI in northeastern China would be too low if its TTCS parameter had higher values. Furthermore, higher TTCS values would not be consistent with the known distribution of $\mathrm{ACB}$ in northeastern China, where it is widespread and causes high damage levels. THCS were adjusted iteratively to fit the distribution boundaries for ACB.

2.6.4 Heat stress

This article is protected by copyright. All rights reserved. 
Heat stress was increased by setting the heat stress temperature (TTHS) to $33^{\circ} \mathrm{C}$ and heat stress accumulation (THHS) to 0.002 week $^{-1}$, to prevent southern parts of Indochina and other tropical areas becoming suitable.

\subsubsection{Diapause index}

In its subtropical and temperate geographical range, ACB enters a facultative cold diapause in the late larval stage from late summer to early spring. ${ }^{22}$ Diapause has been studied in different parts of the species range, including China and Japan. In general, declining photoperiod experienced by the larval stage determines the proportion of the population entering cold diapause, with warm temperatures and photoperiod in spring determining the timing of termination. ${ }^{22,46}$ In China, Guo et $a l .{ }^{47}$ noted that the critical day lengths for diapause induction of $\mathrm{ACB}$ among four geographic populations declined from the north towards the south and the sensitivity to photoperiod also declined from north to south populations. At the same time, the critical day length would be shortened when the rearing temperature increased from 20 to $27^{\circ} \mathrm{C}$. We set the diapause induction daylength to 14.88 hours, the induction temperature to $17^{\circ} \mathrm{C}$ and the termination temperature to $6^{\circ} \mathrm{C}$. These values were obtained from $\mathrm{Lu}$ and 
Zhou $^{48}$ and then iteratively fitting the growth index around population observations from Yang et $a l^{46}$.

\subsection{Modelling for O. nubilalis (ECB) in Europe and North America}

\subsubsection{Temperature index}

The mean lower developmental threshold was $10^{\circ} \mathrm{C}$ in previous modelling attempts. ${ }^{45,49}$ In the current study, the minimum temperature for development (DV0) was set at $5.5^{\circ} \mathrm{C}$ to capture the northern distribution points in Scandinavia better; the lower and upper optimum temperatures (DV1, DV2) were set at 28 and $38^{\circ} \mathrm{C}$, respectively.; in line with parameter estimation from Maiorano et al. ${ }^{49}$, we set the upper limit to $41^{\circ} \mathrm{C}$.

\subsubsection{Moisture index}

Moisture index values limited the establishment of $O$. nubilalis in central America and across the mountain areas. The lower soil moisture limit for development (SM0) was set to 0.06 to indicate the lowest moisture threshold points. The lower and upper 
limits for optimal growth (SM1, SM2 and SM3) were set to levels considered biologically reasonable for current distributions, which were $0.15,1.2$ and 2 , respectively.

\subsubsection{Cold, dry and heat stress}

As the temperature index for $O$. nubilalis alone was able to define the northern (colder) range, adjustments of cold stress parameters were not expected to affect the model outcome and were omitted. Dry stress relates to the moisture index and was set to 0.05 for dry stress threshold (SMDS); -0.04 week $^{-1}$ for dry stress rate (HDS). Heat stress was lowered, by increasing heat stress temperature (TTHS) to $30.5^{\circ} \mathrm{C}$ and heat stress accumulation (THHS) to $0.01 \mathrm{week}^{-1}$ to prevent southern parts of USA and Mexico becoming suitable. Parameters used in CLIMEX models are listed in Table 1.

\subsubsection{Diapause index}

The diapause induction daylength and temperature were set at 14.5 hour and $12^{\circ} \mathrm{C}$ in previous modelling attempts. ${ }^{45,49}$ In the current study, the diapause termination temperature was lowered to $10^{\circ} \mathrm{C}$, capturing emergence time of $\mathrm{ECB}$ adult for 
Pontevedra in north-western Spain better. ${ }^{50}$

The CLIMEX model for ECB was compared to previous model results from Trnka et $a l .{ }^{51}$ and Svobodová et $a l .{ }^{52}$. Because CLIMEX also models the weekly suitability of climate for population growth, it is possible to verify phenology as well as different geographical establishments. ${ }^{30}$ The modelled growth index phenology $\left(\mathrm{GI}_{\mathrm{w}}\right)$ was compared to field moth capture numbers from two locations in Spain (Pontevedra \& Barrantes) for $O$. nubilalis validation in Europe. ${ }^{50}$ For North America, we tested our model performance with published data points. ${ }^{26,53,54}$

\subsection{Parameters for T. ostriniae}

\subsubsection{Temperature index}

Lower developmental thresholds were around 11.7 to $11.8^{\circ} \mathrm{C}$ for $T$. ostriniae. ${ }^{55}$ In the current study, the minimum temperature for development (DV0) was set at $11.7^{\circ} \mathrm{C}$. The lower and upper optimum temperatures (DV1) were set at 22 and $29^{\circ} \mathrm{C}$, respectively. ${ }^{29}$. The upper temperature threshold for both species was close to $33-35^{\circ} \mathrm{C}$, so the upper threshold temperature (DV3) was set at $35^{\circ} \mathrm{C}$. 


\subsubsection{Cold stress}

For T. ostriniae cold stress temperature threshold (TTCS) and cold stress accumulation rate (THCS) were set to $1^{\circ} \mathrm{C}$ and -0.0001 week $^{-1}$. THCS thus were adjusted iteratively to fit the distribution boundaries for T. ostriniae.

\subsection{Host-parasitoid dynamics under climate change in Asia and North America}

To explore possible host-parasitoid dynamics in distribution under climate change for ACB and T. ostriniae in Asia, and for ECB and T. ostriniae in North America, we used the CSIRO Mk. 3.0 models (available from CliMond) ${ }^{30}$ for the year 2080 under the A1B SRES for future climate change, one of the higher rates of warming in the Fourth Assessment Report (AR4). ${ }^{56}$ We further investigated the impact of the predicted changes by plotting the difference in the GI for both corn borers $(\mathrm{ACB} / \mathrm{ECB})$ and the GI for T. ostriniae as a proportion of the GI for ACB/ECB in Asia and North America, and presented proportions as a measure of the likely effectiveness of $T$. ostriniae as an inundative biological control agent among those two continents.

This article is protected by copyright. All rights reserved. 


\section{RESULTS}

\subsection{Distribution fit and model projections for $O$. furnacalis and $T$. ostriniae in}

Asia

The predicted native range of $\mathrm{ACB}$ overlaps with the main corn production areas that are within northeastern (Heilongjiang, Jilin and Shenyang provinces), eastern (Beijing, Hebei, Henan, Shandong, Shanxi, Jiangsu and Anhui provinces), and southeastern (Guangdong, Guangxi and Yunnan including Hainan provinces) China, Japan and southwestern coastal regions of Taiwan (Figs 2a \& 2c). The predicted range of $T$. ostriniae (Figs 2b \& 2d) is similar to its host O. furnacalis, except for its more constrained northern limits in China and Japan, and there are no presence data for Hainan Island.

Variable importance was similar and a final suite of five variables was common to both species after our selection procedure (Table 2). MAXENT performed well in terms of AUC scores, estimated on held-out cross-validation data within the training areas (Table 2). Varying locations up to $20 \mathrm{~km}$ did not significantly change model 
predictions (Appendix S1). 'Mean temperature of wettest quarter $\left({ }^{\circ} \mathrm{C}\right)$ ' (bio08) was the most influential variable for the two species; precipitation and radiation seasonality (bio15 \& bio23) were also important, each contributed more than $10 \%$ (Table 2). CLIMEX predicted suitable areas of $O$. furnacalis in Jiangsu and Yunnan (Figs. 2a \& 2c), whereas MAXENT predicts the constrained distribution of $T$. ostriniae well in Jiangsu, Gansu, Shaanxi and Hainan provinces, although its performance tended to be over-conservative in Yunnan province (Figs. 2b \& 2d).

Figure 3 shows the response curves for the variables used in our MAXENT models. Each curve represents the response to a specific variable with all others set constant, and should therefore be interpreted cautiously, although comparisons between species and models do allow for testable biogeographical insights. ${ }^{42}$ The responses indicate that the distributions of both species are correlated with mean temperature of wettest quarter in summer rainfall corn production regions (bio08) in the range $10-29^{\circ} \mathrm{C}$ (Fig. 3), with both species preferring areas with higher summer precipitation and precipitation seasonality (bio18 \& bio15) within areas that possess moderate isothermality (bio03). Overall, the shape of response curves is similar between ACB 
and T. ostriniae, although the starting points for precipitation and radiation seasonality were higher for ACB. The response curve displayed an opposite trend to radiation seasonality in ACB. This difference suggests that T. ostriniae is more sensitive to climatic seasonality. Permutation importance of precipitation and radiation seasonality in both species models was 18.13 and 23.33 respectively for $T$. ostriniae, compared to 14.08 and 10.03 respectively for ACB (Table 2).

\subsection{Distribution fit and model projections for $O$. nubilalis and $T$. ostriniae in}

\section{Europe and North America}

The locations for inundative release for $T$. ostriniae are within central and northeastern locations of USA and Canada (Kentucky, Virginia, Massachusetts, New York states and Quebec, Fig. 1). Each of the final variable sets used in the MAXENT, PCA analysis and MESS map for North American projections (see Appendix S2 for detail) indicated accessible climate space available to $T$. ostriniae distributed in native Asia is not accessible in novel North America regions. Dissimilar climate space between those two continents might have constrained the MAXENT projection for $T$.

This article is protected by copyright. All rights reserved. 
ostriniae, thus, only the CLIMEX model was adopted for model projection across continents.

The modelled native distribution of $O$. nubilalis distributes across whole Europe areas including England and the southern margin of the Scandinavian peninsula (Fig. 4). The distribution is consistent with model results from Trnka et al. ${ }^{51}$ and Svobodová et al. ${ }^{52}$ in Czech Republic and most European areas, taking into account the use of different climate backgrounds here, and the expected minor idiosyncrasies between datasets. Another test of the CLIMEX model is to generate weekly changes in $\mathrm{GI}_{\mathrm{w}}$ over an average year for a location and compare this "modelled suitability" with observed phenology based on trapping of adult moths (Fig. 4). $\mathrm{GI}_{\mathrm{w}}$ would be expectd to be an indicator of population growth rate for $O$. nubilalis. For both sites, trapped moths occur at times which are climatically suitable for growth, with a seven-week delay for adults observed in Barrantes (northwestern Spain). Moth numbers will of course reflect additional landscape level effects of crop availability and "management", such as extensive and intensive spraying of insecticides. ${ }^{57,58}$ 
The modelled distribution of $O$. nubilalis in North America overlaps with the main corn production areas and published distribution points for $O$. nubilalis ${ }^{26,53,54}$ that are within northeastern United States (Iowa, Illinois, Indiana, Ohio and nearby areas) and Canada (Quebec) (Fig. 5a). Moreover, there is contiguous suitable habitat across southeastern states for the modelled distribution of T. ostriniae (Fig. 5b).

\subsection{Host-parasitoid dynamics under climate change in Asia and North America}

Using the difference in GI between $\mathrm{ACB} / \mathrm{ECB}$ and T. ostriniae allows us to comment on the effectiveness of $T$. ostriniae as a biological control agent under current and future condition. Current climates in Asia are predicted to favor T. ostriniae over ACB across China (Figure 6a, purple shading), ACB only has higher GI in the Sichuan area (Figures 6a, yellow shading). By 2080, it is predicted to favor T. ostriniae over ACB in northeastern China as the difference between GI for ACB and GI for T. ostriniae increases in these regions. On the other hand, GI of $\mathrm{ACB}$ is predicted to decline through the Sichuan area (Figure 6b, previously yellow shading (Figure 6a) changes to light purple shading). The predicted higher temperatures by 2080 is likely to favor T. ostriniae in southern China, where GI for the parasitoid is predicted to be greater 
than GI for ACB (Figure 3c, light purple shading (Figure 6b) changes to dark purple shading).

For North America projections, the climate change scenario is predicted to favor $T$. ostriniae over ECB in the area with least difference presented around most of the US and Canada except some southern area (Figure 6c). By 2080, there is a northward shifting tendency for these areas (Figure 6d). The predicted higher temperatures by 2080 could favor T. ostriniae from regions in southern Canada (Figure 6d, dark purple shading) as the difference between GI for ECB and GI for T. ostriniae decreases in these regions. At the same time, higher temperature is predicted to favor ECB in most southern US, where their GI difference is predicted to be amplified (Figure 6d, light purple shading (Figure 6c) changes to yellow and light-yellow shading).

\section{DISCUSSION AND CONCLUSIONS}

Understanding the extent to which host-parasitoid relationships may be altered by climate change has important implications for future biological control release programs. Identifying where putative spatial mismatch between species may occur is 
particularly important. By employing modelling methods appropriate to the data available on the Asian and European corn borers (ACB and ECB, respectively), and the Trichogramma parasitoid (T. ostriniae), we identified broad scale patterns that provide insights into the importance of precipitation and radiation seasonality that might determine the distribution of a pestiferous host (ACB) and its parasitoid ( $T$. ostriniae). Our analyses also enabled identification of suitable areas for inundative release of T. ostriniae, which convey areas of likely successful parasitism.

As for most insects, temperature is the key factor that determines the distribution of parasitoids and their hosts across multiple scales. ${ }^{17,59}$ Differences in thermal requirements appear to be responsible for large discrepancies between host and parasitoid distributions. In northern areas of Asia where our models typically predicted more suitable climate space for ACB over $T$. ostriniae under current conditions, two factors might contribute. First, the lower development temperature threshold of T. ostriniae is higher than that of its host $\left(6.8\right.$ to $10.4^{\circ} \mathrm{C}$ for $\mathrm{ACB} ; 11.7$ to $11.8^{\circ} \mathrm{C}$ for T. ostriniae). ${ }^{22,55}$ Second, ACB demonstrates broader thermal requirements for development than $T$. ostriniae, which may reflect geographical variation in 
physiological thermal limits; Xie et $a l .{ }^{60}$ previously noted variation in the supercooling point (SCP) and survival rate after low temperature treatments in this species, with mean SCP significantly declining from $-22^{\circ} \mathrm{C}$ in a tropical population (Haikou, $\mathrm{N} 19.98^{\circ}$ ) to $-28.5^{\circ} \mathrm{C}$ for a univoltine low temperature population (Gongzhuling, $\mathrm{N} 43.55^{\circ}$ ).

For southern areas of Asia, T. ostriniae appears to be more sensitive to the lower seasonality of radiation and precipitation (Fig. 3) than its host. The different responses of $T$. ostriniae and ACB to seasonality of both precipitation and radiation reflect findings from a meta-analysis for Trichogramma parasitism, ${ }^{61}$ which found that parasitism was higher in regions with less temperature and precipitation seasonality. Trichogramma displays a more restricted climate tolerance than its hosts as the modelling approach is based on occurrence data, and the occurrence and abundance of Trichogramma is dependent on the abundance of its hosts. Occurrence data for the hosts are relatively better than for Trichogramma parasitoids. At the edge of the geographical range of the hosts, we expect low host population densities and thus low parasitoid densities, making parasitoids particularly hard to detect. As a result, the 
abiotic tolerance of the parasitoid is estimated as being lower. However, this may also reflect the poor mobility of the parasitoid compared to its host (suggesting that the parasitoid cannot easily track changes in favorable conditions, and, being restricted to the static egg stage of its $\mathrm{ACB}$ host, is more exposed to extreme temperature and precipitation), or the dependence of $T$. ostriniae on passive transport (mainly wind dispersion), compared to its larger bodied lepidopteran hosts. ${ }^{62,63}$

The Ecoclimatic index of $T$. ostriniae and its host ECB in North America were associated with different temperature, moisture, dry and heat stress parameters. In low latitudes of North America, we found that there is more suitable climate space for $T$. ostriniae than ECB (Fig. 5), which is different from predictions in Asia, despite the upper development temperature threshold being higher for the host $\left(41^{\circ} \mathrm{C}\right.$ for $\mathrm{ECB}$; $35^{\circ} \mathrm{C}$ for $T$. ostriniae). ${ }^{49,55}$ In this case we suspect that much lower heat stress temperature $\left(30.5^{\circ} \mathrm{C}\right.$ for $\mathrm{ECB} ; 35^{\circ} \mathrm{C}$ for $T$. ostriniae $)$ and higher heat stress accumulation for ECB $\left(0.01\right.$ week $^{-1}$ for ECB; 0.02 week $^{-1}$ for $T$. ostriniae $)$ reflect constrained growth and dispersion in southern areas of North America. 
Constructing niche models at a global scale inherently assumes that all populations respond to predictor variables, or ecophysiological indices, in much the same way. This is highly unlikely, as differences in temperature-related life history parameters for T. ostriniae are likely to exist. For example, individuals from North American populations grow faster than Chinese populations ( 9 days at $24^{\circ} \mathrm{C}$ for America; 10 to 11 days at $25^{\circ} \mathrm{C}$ for China). ${ }^{29}$ There may also be genetic differentiation among North America populations of ECB related to voltinism. ${ }^{53}$ Such differences could influence the successful establishment of T. ostriniae populations in new areas. For species that encompass large geographic ranges, it can be challenging to define diapause as a single function for all populations. For ACB and ECB there are different strains and varying responses to light and temperature according to latitude. ${ }^{47,60,64}$ Whilst we have fitted single diapause indices to these species, it should be noted that regional assessments of distributions and field efficacy will need to identify specific temperature limits and diapause cues for the local populations. Additionally, identifying different populations and strains through genetic methods could allow for partitioning correlative models like MAXENT to investigate species-environment relationships at finer scales. ${ }^{65}$ 
The underprojection of the T. ostriniae Asia-trained MAXENT model into North America highlights some potential limits of extrapolating correlative models. ${ }^{8}$ Dissimilar climate space between continents may have constrained the modelling projections presented here (Appendix S2). However, the CLIMEX models were able to project from the native occurrence points without these issues, reinforcing both the importance of comparing different modelling approaches, and using physiologically based approaches (i.e. CLIMEX) when projecting to novel areas of climates as well ${ }^{11,39}$ Distribution data for both $T$. ostriniae and $O$. furnacalis were limited due to recent survey efforts being restricted regionally and a lack of precise locality data associated with most published records. ${ }^{66,67}$ Our modelling approaches consider these two species in isolation, and inherently overlook competitive interactions with other Trichogramma species present across the distributions. Meta-analyses have suggested for competing natural enemy species that antagonism may result in effects on the target being less than additive, and this deleterious outcome is most obvious when the same life stage of a host is attacked. ${ }^{15}$ Therefore, any inference regarding areas suitable for T. ostriniae ought to be made with caution and requires empirical studies 
that include molecular identification of potential competing Trichogramma species that might have been incorrectly identified. ${ }^{23,68}$

In terms of biological control, there are perhaps implications for areas with GI differences that favour the parasitoid over the host (Fig. 6a \& 6c). Such areas may represent increased efficacy of the parasitoid wasp in those parts of Asia and North America and indicate areas with a higher probable success rate of inundative releases. In areas where $T$. ostriniae is in marginal climate space, the efficiency of biocontrol might be improved through increasing the number of wasps used in inundative releases. ${ }^{21}$ For example, Gagnon et al. ${ }^{26}$ recently reported that the use of $T$. ostriniae around Quebec (marginally suitable in our models) could effectively decrease the pressure exerted by ECB and its damage on sweet corn ears. Biocontrol efficiency might also be improved by timing releases to avoid extreme radiation/rainfall events based on meteorological forecasts. Better regional temporal forecasts should emerge by considering host-parasitoid relationships through dynamic population models that consider the interaction between trophic levels. 
Under the future climate change scenarios investigated here, both ACB and $T$. ostriniae are expected to have broad geographic distribution in southeastern Asia into the next few decades. While this suggests a reasonable level of biological control potential for the future, there are also some likely challenges. The high degree of variation in life history traits within $\mathrm{ACB}$ populations across $\mathrm{Asia},{ }^{21,22}$ and the occurrence of multiple generations per year, could provide opportunities for rapid adaptation to novel environments. ${ }^{11,60}$ Areas representing a relative advantage for ECB through the central United States (Fig. 6d) contain low similarity to Asian climate space of $T$. ostriniae (Appendix S2), which might limit its control efficacy across central North America in the future. To sum up, the efficacy of T. ostriniae biocontrol across areas of northern America and Canada is likely to be effectively improved under warming temperature around summer. ${ }^{26,61}$ Control efforts through central North America area, on the other hand, may be improved by increasing the numbers and release frequency of $T$. ostriniae and optimizing corn integrated control strategies based on further phenological dynamics studies.

Overall the modelling approaches used here proved useful for examining broad-scale 
environmental limits to an egg parasitoid and its lepidopteran hosts. Global investigations provide important hypotheses on key traits that limit distributions and define synchrony in host-parasitoid relationships. Such hypotheses can help to guide future experimental work to understand how climate change, such as climate seasonality/extremity, may affect these species at finer-scales. We also identified areas potentially suitable for inundative releases, however more regional-scale assessments will need to determine which strains of the hosts are present to determine how important life-history traits such as diapause are represented in local populations. Finally, further phenological and diapause studies for $T$. ostriniae and its hosts are required to optimize corn integrated control strategies.

\section{Acknowledgements}

We are grateful to the scientists who conducted and published their distribution studies. AAH was supported by fellowships from the Australian Research Council and the National Health and Medical Research Council. 


\section{References}

1. Lesk C, Rowhani P and Ramankutty N, Influence of extreme weather disasters on global crop production. Nature 529: 84-87 (2016).

2. Dunn RR, Harris, NC, Colwell, RK, Koh, LP and Sodhi NS, The sixth mass coextinction: are most endangered species parasites and mutualists? $P R$ Soc $B$ 276(1670): 3037-3045 (2009).

3. Thomson LJ, Macfadyen S and Hoffmann AA, Predicting the effects of climate change on natural enemies of agricultural pests. Biol Control 52(2): 296-306 (2010).

4. Furlong MJ and Zalucki MP, Climate change and biological control: the consequences of increasing temperatures on host-parasitoid interactions. Curr Opin Insect Sci 20: 39-44 (2017).

5. Guisan A and Thuiller W, Predicting species distribution: offering more than simple habitat models. Ecol lett 8(9): 993-1009 (2005).

6. Franklin J, Mapping Species Distributions: Spatial Inference and Prediction. Cambridge University Press, Cambridge, UK (2009).

7. Franklin J, Species distribution models in conservation biogeography: 
developments and challenges. Divers Distrib 19(10): 1217-1223 (2013).

8. Hill MP and Thomson LJ, Species distribution modelling in predicting response to climate change, in Climate Change and Insect Pests, ed. by Björkman $\mathrm{C}$ and Niemelä P, CABI. Oxfordshire, pp. 16-37 (2015).

9. Elith J, Kearney $\mathrm{M}$ and Phillips $\mathrm{S}$, The art of modelling range-shifting species. Methods Ecol Evol 1(4): 330-342 (2010).

10. Hill MP, Bertelsmeier C, Clusella-Trullas S, Garnas J, Robertson MP and Terblanche JS, Predicted decrease in global climate suitability masks regional complexity of invasive fruit fly species response to climate change. Biol Invasion 18(4): 1105-1119 (2016).

11. Lozier JD and Mills NJ, Predicting the potential invasive range of light brown apple moth (Epiphyas postvittana) using biologically informed and correlative species distribution models. Biol Invasions 13: 2409-2421 (2011).

12. Sutherst RW, Maywald GF and Kriticos D, CLIMEX Version 3: User's Guide. Hearne Scientific Software Pty Ltd, Melbourne (2007).

13. Robertson MP, Kriticos DJ and Zachariades C, Climate matching techniques to narrow the search for biological control agents. Biol Control 46(3): 442-452

This article is protected by copyright. All rights reserved. 
(2008).

14. Senaratne KADW, Palmer WA and Sutherst RW, Use of CLIMEX modelling to identify prospective areas for exploration to find new biological control agents for prickly acacia. Aust J Entomol 45(4): 298-302 (2006).

15. Hoddle MS, Warner K, Steggall J and Jetter KM, Classical biological control of invasive legacy crop pests: New technologies offer opportunities to revisit old pest problems in perennial tree crops. Insects 6(1): 13-37 (2015).

16. Smith SM, Biological control with Trichogramma: Advances, successes, and potential of their use. Annu Rev Entomol 41: 375-406 (1996).

17. Hance $T$, van Baaren $J$, Vornon $P$ and Boivin $G$, Impact of extreme temperatures on parasitoids in a climate change perspective. Annu Rev Entomol 52: 107-126 (2007).

18. Le Roux $\mathrm{RC}$ and McGeoch MA, Rapid range expansion and community reorganization in response to warming. Glob Change Biol 14(12): 2950-2962 (2008).

19. Walther G, Community and ecosystem responses to recent climate change. Philos TR Soc Lon B 1549(365): 2019-2024 (2010).

This article is protected by copyright. All rights reserved. 
20. Stireman JO III, Dyer LA, Janzen DH, Singer MS, Lill JT, Marquis RJ, Ricklefs RE, Gentry GL, Hallwachs W, Coley PD, Barone JA, Greeney, HF, Connahs H, Barbosa P, Morais HC and Diniz IR, Climatic unpredictablility and parasitism of caterpillars: Implications of global warming. P Natl Acad Sci USA 48(102): 17384-17387 (2005).

21. Wang ZY, He KL, Zhang F, Lu X and Babendreier D, Mass rearing and release of Trichogramma for biological control of insect pests of corn in China. Biol Control 68: 136-144 (2014).

22. Nafus DM and Schreiner IH, Review of the biology and control of the Asian corn borer, Ostrinia furnacalis (Lep: Pyralidae). Trop Pest Manage 37(1): 41-56 (1991).

23. Wu LH, Hoffmann AA and Thomson LJ, Trichogramma parasitoids for control of Lepidopteran borers in Taiwan: species, life-history traits and Wolbachia infections. J Appl Entomol 140(5): 353-363 (2016).

24. Wang B, Ferro DN and Hosmer DW, Importance of plant size, distribution of egg masses, and weather conditions on egg parasitisms of the European corn borer,

This article is protected by copyright. All rights reserved. 
Ostrinia nubilalis by Trichogramma ostriniae in sweet corn. Entomol Exp Appl 83(3): 337-345 (1997).

25. Etilé E, Boisclair J, Cormier D, Todorova S and Lucas É, Evaluation of two biological control strategies against the European corn borer (Ostrinia nubilalis) in southern Quebec fresh sweet corn, in 4ème Conférence Internationale sur les Méthodes Alternatives en Protection des Cultures. Evolution des cadres réglementaires européen et français, Nouveaux moyens et stratégies Innovantes, Nouveau Siècle, Lille, France, pp. 614-620 (2011).

26. Gagnon AE, Audette C, Duval B and Boisclair J, Can the use of Trichogramma ostriniae (Hymenoptera : Trichogrammatidae) to control Ostrinia nubilalis (Lepidoptera : Crambidae) be economically sustainable for processing sweet Corn ? J Econ Entomol 110(1): 59-66 (2016).

27. Seaman A, Hoffmann H, Gardner J and Chenus S, Pilot testing of Trichogramma ostriniae releases in fresh market sweet corn for control of European corn borer, in New York State Vegetable Project Reports Relating to IPM, NY IPM Publication 121, pp. 149-154. (1996).

28. Hoffmann MP, Pitcher SA, Cheever SA, Gardner J, Losey JE, Kuhar TP, Laub CA

This article is protected by copyright. All rights reserved. 
and Youngman RR, Efficacy of inoculative releases of Trichogramma ostriniae (Hymenoptera: Trichogrammatidae) against European corn borer Ostrinia nubilalis (Lepidoptera: Crambidae) in Weld corn. Biol Control 36(3): 345-349 (2006).

29. Wang B, Ferro DN, Wu J and Wang S, Temperature-dependent development and oviposition behavior of Trichogramma ostriniae (Hymenoptera: Trichogrammatidae), a potential biological control agent for the European corn borer (Lepidoptera: Crambidae). Environ Entomol 33(4): 787-793 (2004).

30. Kriticos DJ, Webber BL, Leriche A, Ota N, Macadam I, Bathols J and Scott JK, CliMond: global high-resolution historical and future scenario climate surfaces for bioclimatic modelling. Methods Ecol Evol 3(1): 53-64 (2012).

31. Phillips SJ, Anderson RP and Schapire RE, Maximum entropy modeling of species geographic distributions. Ecol Model 190(3-4): 231-259 (2006).

32. Elith J, Phillips SJ, Hastie T, Dudík M, Chee Y and Yates CJ, A statistical explanation of MAXENT for ecologists. Divers Distrib 17(1): $43-57$ (2011).

33. Hijmans RJ, Cameron S, Parra JL, Jones PG and Jarvis A, Very high resolution

This article is protected by copyright. All rights reserved. 
interpolated climate surfaces for global land areas. Int J Climatol 25(15): 1965-1978 (2005).

34. New M, Lister D, Hulme M and Makin I, A high-resolution data set of surface climate over global land areas. Clim Res 21(1): 1-25 (2002).

35. Barve N, Barve V, Jiménez-Valverde A, Lira-Noriega A, Maher SP, Peterson AT, Soberón J and Villalobos F, The crucial role of the accessible area in ecological niche modeling and species distribution modeling. Ecol Model 222(11): 1810-1819 (2011).

36. Hirzel AH, Hausser J, Chessel D and Perrin N, Ecological-niche factor analysis: how to compute habitat-suitability maps without absence data? Ecology 83(7): 2027-2036 (2002).

37. Calenge $\mathrm{C}$, The package 'adhabitat' for the R software: a tool for the analysis of space and habitat use by animals. Ecol Model 197(3-4): 516-519 (2006).

38. $\mathrm{R}$ Core Team, R: A language and environment for statistical computing. $\mathrm{R}$ foundation for statistical computing, Vienna, Austria. ISBN 3-900051-07-0 (2014).

39. Hill MP, Axford J and Hoffmann AA, Predicting the spread of Aedes albopictus in

This article is protected by copyright. All rights reserved. 
Australia under current and future climates: Multiple approaches and datasets to incorporate potential evolutionary divergence. Austral Ecol 39(4): 469-478 (2014).

40. Rödder D and Lötters S, Niche shift versus niche conservatism? Climatic characteristics of the native and invasive ranges of the Mediterranean house gecko (Kemidactylus turcicus). Global Ecol Biogeogr 18(6): 674-687 (2009).

41. Hill MP and Terblanche JS, Niche overlap of congeneric invaders supports a single-species hypothesis and provides insight into future invasion risk: implications for global management of the Bactrocera dorsalis complex. PLoS One 9(2): e90121(2014).

42. Hill MP, Hoffmann AA, Macfadyen S, Umina PA and Elith J, Understanding niche shift: using current and historical data to model the invasive redlegged earth mite, Halotydeus destructor. Divers Distrib 18(2): 191-203 (2012).

43. Hijmans RJ, Phillips S, Leathwick J and Elith J, Package 'dismo'. Available online at: http://cran.r-project.org/web/packages/dismo/index.html (2011).

44. Sutherst RW and Maywald GF, A climate-model of the red imported fire ant, Solenopsis invicta Buren (Hymenoptera: Formicidae): implications for invasion

This article is protected by copyright. All rights reserved. 
of new regions, particularly Oceania. Environ Entomol 34(2): 317-335 (2005).

45. Kocmánková E, Trnka M, Eitzinger J, Formayer H, Dubrovský M, Semerádová D, Žalud Z, Juroch J and Možný M, Estimating the impact of climate change on the occurrence of selected pests in the Central European region. Clim Res 44(1): 95-105 (2010).

46. Yang HZ, Tu XY, Xia QW, He HM, Chen C and Xue FS, Photoperiodism of diapause induction and diapause termination in Ostrinia furnacalis. Entomol Exp Appl 153(1): 34-46 (2014).

47. Guo JQ, Zhang HG, Wang ZY and He KL, Effects of photoperiod and temperature on diapause induction in Ostrinia furnacalis (Lepidoptera: Crambidae). Acta Entomol Sinica 56(9): 996-1003 (2013).

48. Lu X and Zhou DR, On the photoperiodic reactions in different voltinism ecotypes of asian corn borer. J Plant Prot 27: 12-16 (2000).

49. Maiorano A, Bregaglio S, Donatellia M, Fumagalli D and Zucchini A, Comparison of modelling approaches to simulate the phenology of the European corn borer under future climate scenarios. Ecol Model 245(24): 65-74 (2012).

This article is protected by copyright. All rights reserved. 
50. Cordero C, Malvar RA, Butrón A, Revilla P, Velasco P and Ordás A, Population dynamics and life-cycle of corn borers in south Atlantic European coast. Maydica 43: 5-12 (1998).

51. Trnka M, Muška F, Semerádová D, Dubrovský M, Kocmánková E and Žalud Z, European Corn Borer life stage model: Regional estimates of pest development and spatial distribution under present and future climate. Ecol Model 207(2-4): 61-84 (2007).

52. Svobodová E, Trnka M, Dubrovský M, Semerádová D, Eitzinger J, Žalud Z and 't pánek P, Pests occurrence model in current climate-validation study for European domain. Acta U Agr Silvi Mendelianae Brunensis 1: 205-214 (2013).

53. Coates BS, Sumerford DV and Hellmich RL, Geographic and voltinism differentiation among North American Ostrinia nubilalis (European corn borer) mitochondrial cytochrome c oxidase haplotypes. J Insect Sci 4(35): 1-9 (2004).

54. Merrill SC, Walter SM, Peairs FB and Schleip EM, The distribution of European Corn Borer (Lepidoptera : Crambidae) moths in pivot-irrigated corn. $J$ Econ Entomol 106(5): 2084-2092 (2013).

55. Hirashima Y, Miura K, Miura T and Shiro K, Effect of temperature on the 
development of the egg-parasitoids Trichogramma chilonis and Trichogramma ostriniae. Sci B Fac Agr Kyushu 44: 71-76 (1990).

56. Intergovernmental Panel on Climate Change, in Managing the Risks of Extreme Events and Disaster to Advance Climate Change Adaptation, ed. by Field CB, Barros V, Stocker TF, Dahe Q, Dokken DJ, Ebi KL, Mastrandrea MD, Mach KJ, Plattner GK, Allen SK, Tignor M and Midgley PM, Cambridge University Press, Cambridge, pp. 1-19 (2013).

57. Zalucki MP, Adamson D and Furlong MJ, The future of IPM: whither or wither? Aust J Entomol 48(2): 85-96 (2009).

58. Kriticos DJ, Ota N, Hutchison WD, Beddow J, Walsh T, Tay WT, Borchert DM, Paula-Moreas SV, Czepak C and Zalucki MP, The potential distribution of invading Helicoverpa armigera in North America: is it just a matter of time? PLOS ONE 10: e0119618 (2015).

59. Jeffs $\mathrm{T}$ and Lewis OT, Effects of climate warming on host-parasitoid interactions. Ecol Entomol 38(3): 209-218 (2013).

This article is protected by copyright. All rights reserved. 
60. Xie HC, Li DS, Zhang HG, Mason CE, Wang ZY, Lu X, Cai WZ and He KL, Seasonal and geographical variation in diapause and cold hardiness of the Asian corn borer, Ostrinia furnacalis. Insect Sci 22(4): 578-586 (2015).

61. Wu LH, Hoffmann AA and Thomson LJ, Potential impact of climate change on parasitism efficiency of egg parasitoids: A meta-analysis of Trichogramma under variable climate conditions. Agr Ecosyst Environ 231: 143-155 (2016).

62. Romeis J, Babendreier D, Wäckers L and Shanower TS, Habitat and plant specificity of Trichogramma egg parasitoids-underlying mechanisms and implications. Basic Appl Ecol 6(3): 215-236 (2005).

63. Mills N, Egg parasitoids in biological control and integrated pest management, in Egg Parasitoids in Biological Control and Integrated Pest Management, ed. by Consoli FL, Parra JRP and Zucchi RA, Springer, New York, pp. 389-411 (2010).

64. Onstad DW and Brewer EF, Modeling induction of diapause in North American Ostrinia nubilalis (Lepidoptera: Pyralidae) populations. Popul Ecol 25(5): 1140-1146 (1996).

65. Lozier JD and Mills NJ, Ecological niche models and coalescent analysis of gene

This article is protected by copyright. All rights reserved. 
flow support recent allopatric isolation of parasitoid wasp populations in the Mediterranean. PLoS ONE 4: e5901 (2009).

66. Graham CH, Ferrier S, Huettman F, Moritz C and Peterson AT, New developments in museum-based informatics and applications in biodiversity analysis. Trends Ecol Evol 19(9): 497-503 (2004).

67. Pearson RG, Raxworthy CJ, Nakamura M and Peterson AT, Predicting species distributions from small numbers of occurrence records: a test case using cryptic geckos in Madagascar. J Biogeogr 34(1): 102-117 (2007).

68. Wu LH, Hoffmann AA and Thomson LJ, Taiwanese Trichogramma of Asian corn borer: morphology, ITS-2 rDNA characterization, and natural Wolbachia infection. J Insect Sci 16(1): 1-7 (2016b).

This article is protected by copyright. All rights reserved. 


\section{Tables and Figures}

Table 1 CLIMEX parameter values for the final model for Ostrinia furnacalis and Trichogramma ostriniae and Ostrinia nubilalis determined by iteratively changing parameter values until the performance provided best fit to the known native distributions (see Fig. 1)

\begin{tabular}{|c|c|c|c|c|}
\hline \multirow{2}{*}{ Index } & \multirow{2}{*}{ Parameter } & \multicolumn{3}{|l|}{ Value $^{a}$} \\
\hline & & o. furnacalis & T. ostriniae & O. nubilalis \\
\hline \multirow[t]{4}{*}{ Temperature } & DV0 $=$ Lower threshold & $6.8^{\circ} \mathrm{C}$ & $11.7^{\circ} \mathrm{C}$ & $5.5^{\circ} \mathrm{C}$ \\
\hline & DV1 = Lower optimum temperature & $20^{\circ} \mathrm{C}$ & $22^{\circ} \mathrm{C}$ & $28^{\circ} \mathrm{C}$ \\
\hline & DV2 = Upper optimum temperature & $28^{\circ} \mathrm{C}$ & $29^{\circ} \mathrm{C}$ & $38^{\circ} \mathrm{C}$ \\
\hline & DV3 = Upper threshold & $\mathbf{3 3}^{\circ} \mathrm{C}$ & $35^{\circ} \mathrm{C}$ & $41^{\circ} \mathrm{C}$ \\
\hline \multirow[t]{4}{*}{ Moisture } & SM0 $=$ Lower soil moisture threshold & 0.15 & 0.15 & 0.06 \\
\hline & SM1 = Lower optimum soil moisture & 0.35 & 0.35 & 0.15 \\
\hline & SM2 = Upper optimum soil moisture & 0.80 & 0.80 & 1.20 \\
\hline & SM3 = Upper soil moisture threshold & 1.50 & 1.50 & 2.00 \\
\hline \multirow[t]{2}{*}{ Cold stress } & TTCS $=$ Cold stress temperature threshold & $0.5^{\circ} \mathrm{C}$ & $1^{\circ} \mathrm{C}$ & - \\
\hline & THCS $=$ Cold stress accumulation rate & -0.0001 week $^{-1}$ & -0.0001 week $^{-1}$ & - \\
\hline \multirow[t]{2}{*}{ Heat stress } & TTHS $=$ Heat stress temperature threshold & $\mathbf{3 3}^{\circ} \mathrm{C}$ & $35^{\circ} \mathrm{C}$ & $30.5^{\circ} \mathrm{C}$ \\
\hline & THHS = Heat stress accumulation rate & 0.002 week $^{-1}$ & 0.02 week $^{-1}$ & 0.01 week $^{-1}$ \\
\hline \multirow[t]{2}{*}{ Dry stress } & SMDS $=$ Dry stress threshold & 0.1 & 0.1 & 0.05 \\
\hline & HDS $=$ Dry stress rate & -0.02 week $^{-1}$ & -0.02 week $^{-1}$ & -0.04 week $^{-1}$ \\
\hline \multirow[t]{2}{*}{ Wet stress } & SMWS $=$ Wet stress threshold & 1.5 & 1.5 & 1.5 \\
\hline & HWS $=$ Wet stress rate & 0.0002 week $^{-1}$ & 0.0002 week $^{-1}$ & 0.0002 week $^{-1}$ \\
\hline \multirow[t]{2}{*}{ Diapause } & Diapause induction daylength & 14.88 hour & - & 14.5 hour \\
\hline & Diapause induction temperature & $17^{\circ} \mathrm{C}$ & - & $12^{\circ} \mathrm{C}$ \\
\hline
\end{tabular}


${ }^{\text {a } V a l u e s ~ w i t h o u t ~ u n i t s ~ a r e ~ d i m e n s i o n l e s s ~ p r o p o r t i o n s . ~ C o l d ~ s t r e s s ~ p a r a m e t e r s ~ f o r ~}$ O. nubilalis were left blank as these would not affect model outcome.

This article is protected by copyright. All rights reserved. 
Table 2 Sample size and percentage based on mean area under the curve of receiver-operator characteristic (AUC) test gain across 10 cross-validation replicates for MAXENT models; final variable ${ }^{\dagger}$ contributions and importance assessed through MAXENT selected for Trichogramma ostriniae and Ostrinia furnacalis

\begin{tabular}{|c|c|c|c|c|c|c|c|c|c|c|c|c|}
\hline \multirow{3}{*}{ Species } & \multirow{3}{*}{$n$} & \multirow{3}{*}{ AUC } & \multicolumn{10}{|c|}{ Variable contribution and importance } \\
\hline & & & \multicolumn{2}{|c|}{ Bio03 } & \multicolumn{2}{|c|}{ Bio08 } & \multicolumn{2}{|c|}{ Bio15 } & \multicolumn{2}{|c|}{ Bio 18} & \multicolumn{2}{|c|}{ Bio 23} \\
\hline & & & PC & PI & PC & PI & PC & PI & $\mathbf{P C}$ & PI & PC & PI \\
\hline O. furnacalis & 183 & 0.778 & 9.64 & 8.22 & 62.11 & 61.88 & 12.77 & 14.08 & 5.43 & 5.80 & 10.06 & 10.03 \\
\hline T. ostriniae & 129 & 0.854 & 5.10 & 5.27 & $\mathbf{5 8 . 0 7}$ & $\mathbf{5 2 . 4 7}$ & 19.29 & 18.13 & 1.05 & 0.80 & 16.48 & 23.33 \\
\hline
\end{tabular}

${ }^{\dagger}$ Bio03 = Isothermality (mean of monthly (max temp - min temp)/ temperature annual range) $(* 100)$; Bio08 $=$ Mean temperature of wettest quarter $\left({ }^{\circ} \mathrm{C}\right) ;$ Bio15 $=$ Precipitation seasonality (coefficient of variation); Bio18 $=$ Precipitation of warmest quarter; Bio23 = Radiation seasonality (coefficient of variation). PC, percent contribution; PI, permutation importance. 


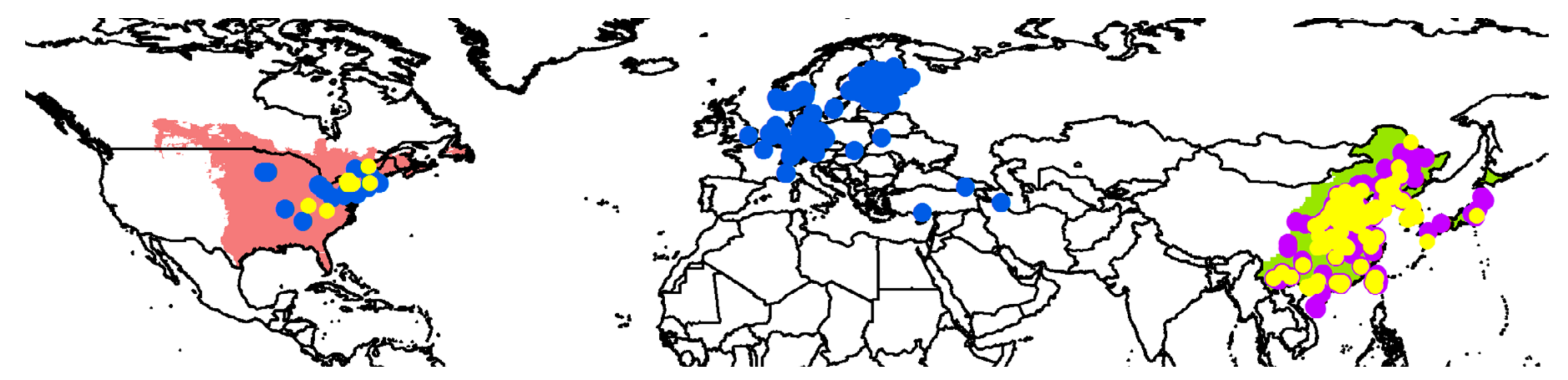

Figure 1 Distributions of Asian corn borer, Ostrinia furnacalis (purple circles), European corn borer, Ostrinia nubilalis (blue circles) and Trichogramma ostriniae (yellow circles). Sources are published references (see Table S1) and field surveys in 2014 and 2015 in China, Japan, Korea and Taiwan. Locations of T. ostriniae inundative releases undertaken in North America from published references (see Table S1). Colored areas represent backgrounds used in Environmental Niche Model (ENMs) construction based on Köppen-Geiger classifications $($ Green $=$ Asia model; Pink $=$ America model). 


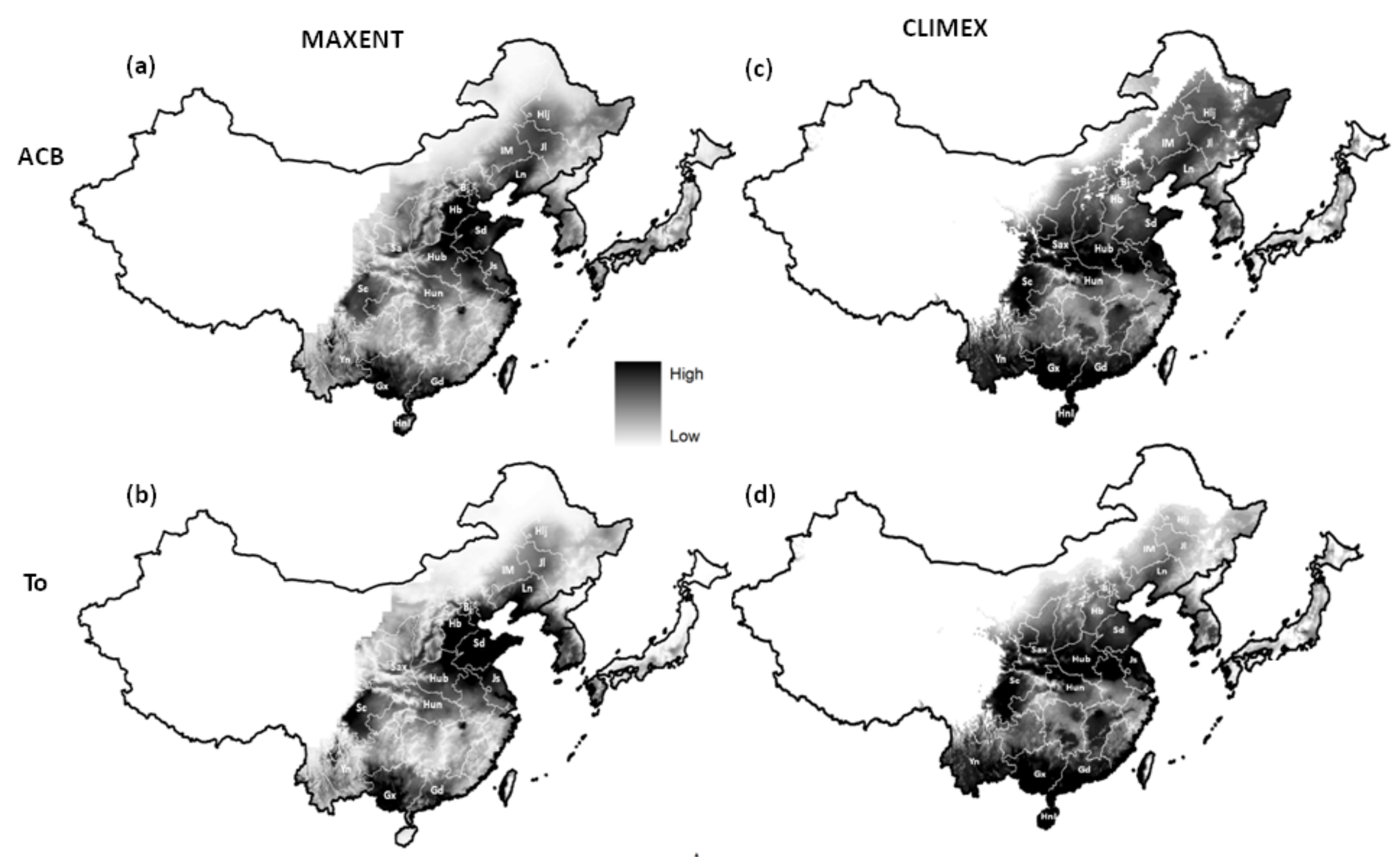


Figure 2 Distribution fitting models between Ostrinia furnacalis (ACB) and Trichogramma ostriniae (To) in southeastern Asia using two different niche modelling approaches. (a) O. furnacalis logistic MAXENT fitting model: MAXENT logistic output as a continuous suitability (01) layer, and darker shading indicates higher climate space suitability. (b) T. ostriniae logistic MAXENT fitting model. (c) O. furnacalis, (d) T. ostriniae CLIMEX fitting model: EI output as a continuous suitability (0-65) layer, and darker shading indicates higher climate space suitability. Provinces are indicated on the map by abbreviations: Ah, Anhui; Bj, Beijing; Fj, Fujian; Gd, Guangdong; Gs, Gansu; Gx, Guangxi; Gz, Guizhou; Hb, Hebei; Hlj, Heilongjiang; Hn, Henan; HnI, Hainan Island; Hub, Hubei; Hun, Hunan; IM, Inner Mongolia; Jl, Jilin; Js, Jiangsu; Jx, Jiangxi; Ln, Liaoning; Sax, Shaanxi; Sc, Sichuan; Sd, Shandong; Sx, Shanxi; Yn, Yunnan; Zj, Zhejiang. 

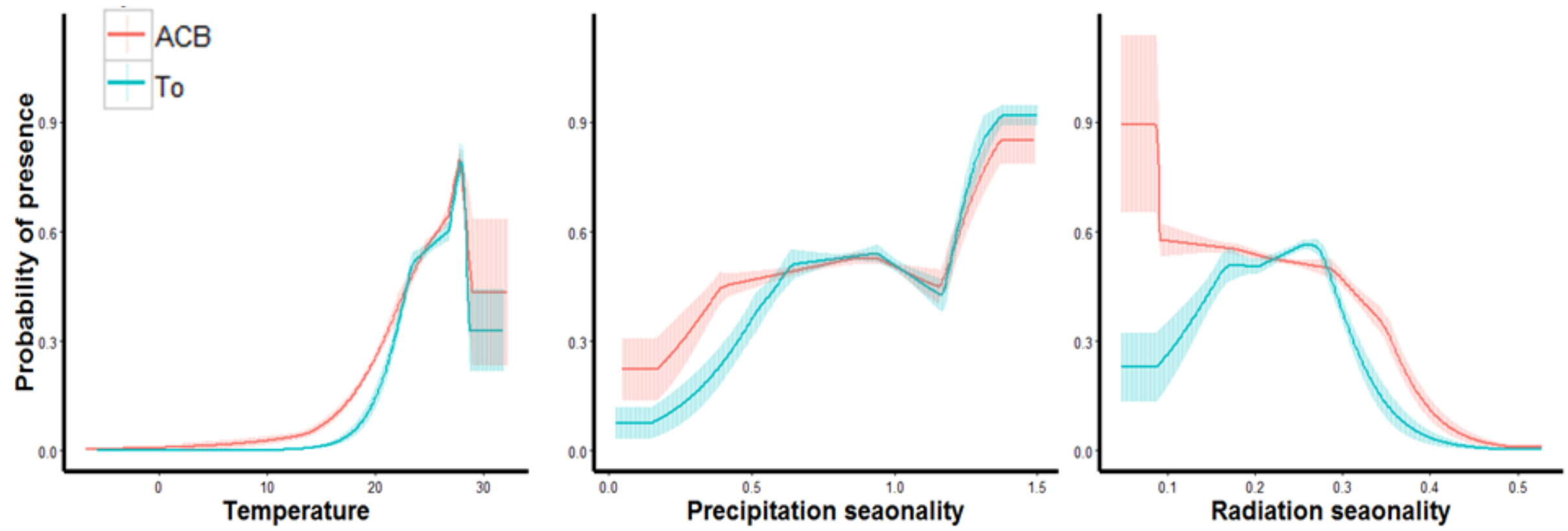

Figure 3 Variable response curves for three dominant predictor variables across models of Ostrinia furnacalis and Trichogramma ostriniae built in MAXENT. The line on the graphs is the mean of 10 cross-validation replicates, and the shaded area is the standard deviation across the replicates. Red: O. furnacalis (ACB); blue: T. ostriniae (To). 


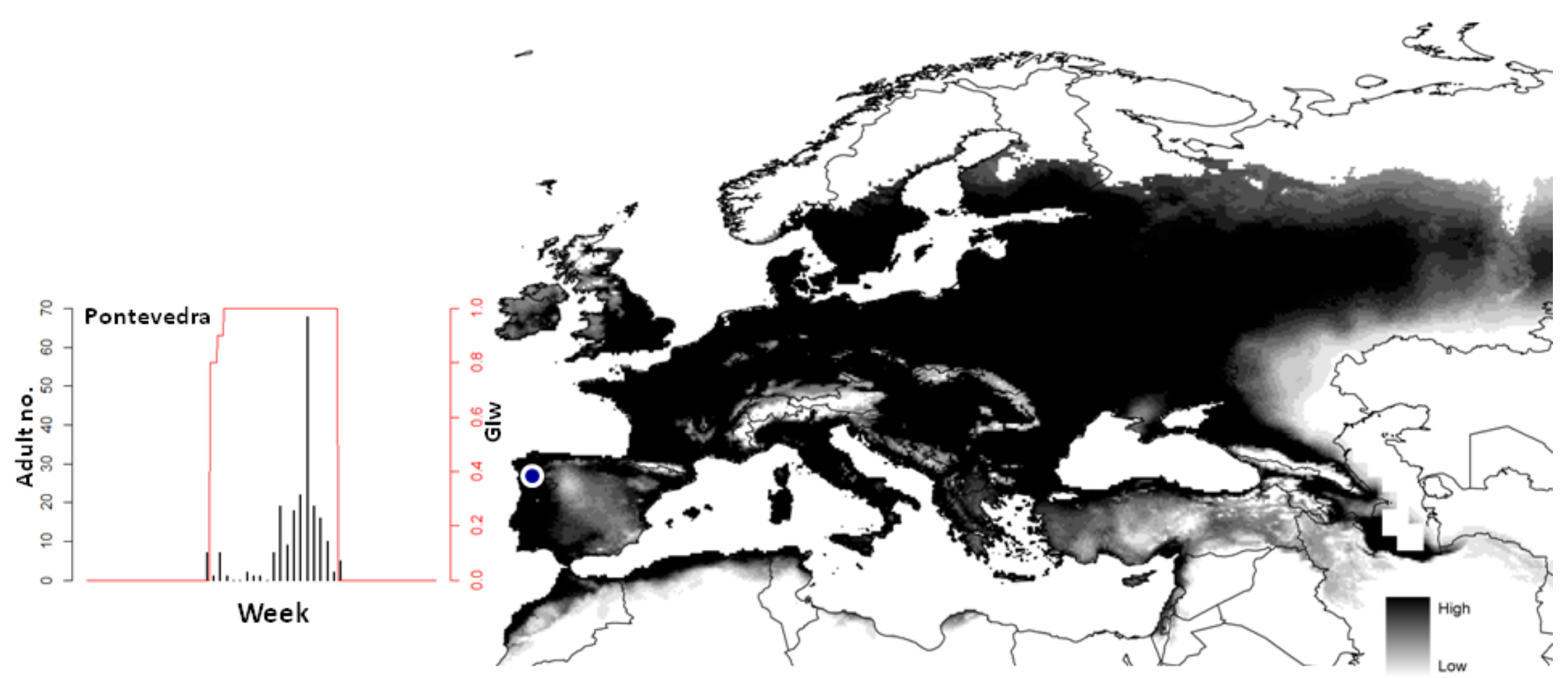

Figure 4 CLIMEX output for European corn borer Ostrinia nubilalis in Europe built on CliMond data sets. Shading reflecting Ecoclimatic Index (EI), and various measures of population abundance for $O$. nubilalis (Major Y-axis) and Weekly Growth Index (minor Y-axis) values over a year derived from current model (time in weeks, 1-52) match with each other in summer for Pontevedra (blue point) in North western Spain (modified from Cordero et al. 1998).

This article is protected by copyright. All rights reserved. 
(a)

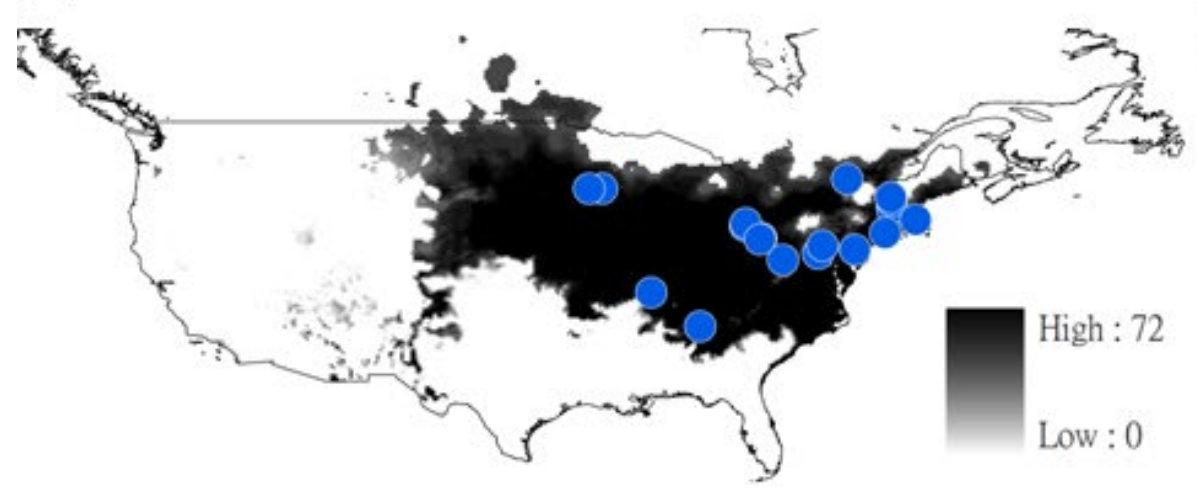

(b)

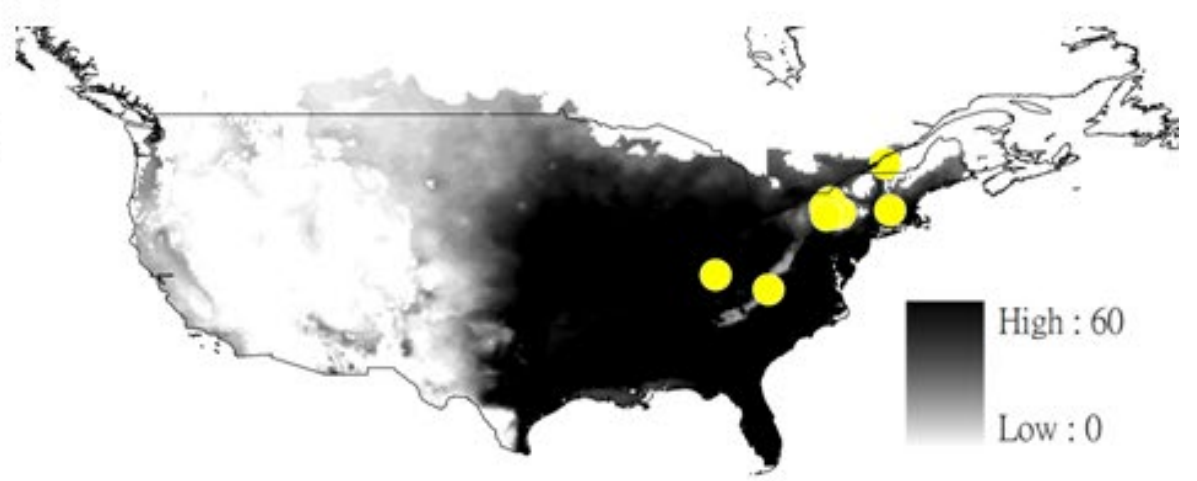

Figure 5 Distribution fitting models between Ostrinia nubilalis and Trichogramma ostriniae in north America built on CliMond data sets. (a) $O$. nubilalis, (b) T. ostriniae CLIMEX fitting EI model: output as a continuous suitability (0-80) layer, and darker shading indicates higher climate space suitability. Blue points represent distribution points of $O$. nubilalis, yellow points represent distribution points of $T$. ostriniae. 


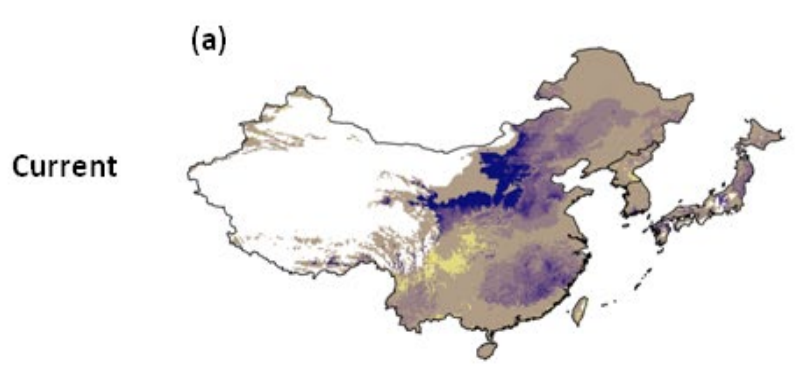

(c)

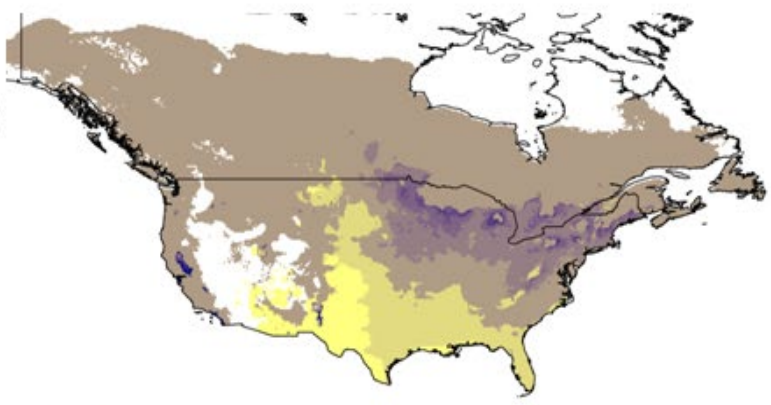

(b)

2080

(d)

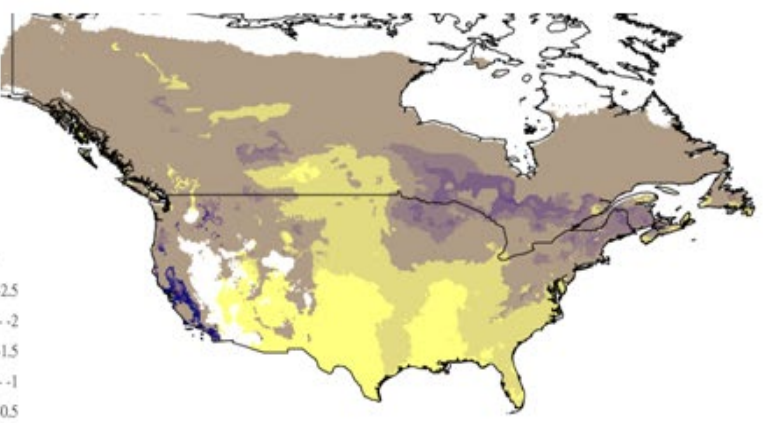

Figure 6 Effects of predicted climate change on the relationships between ACB/ECB and Trichogramma ostriniae in southeastern Asia/north America. Relationship between the current differences between $\mathrm{ACB}, \mathrm{ECB}$ and $T$. ostriniae growth indices (GIs); and the predicted differences in these indices by 2080. (a) Differences between ACB GI and T. ostriniae GI expressed as a proportion of ACB current GI. (b) Predicted differences between ACB GI and T. ostriniae GI expressed as a proportion of ACB GI for 2080. (c) Differences between ECB GI and T. ostriniae GI expressed as a proportion of ECB current GI. (d) Predicted differences between ECB GI and $T$. ostriniae GI expressed as a proportion of ECB GI for 2080. In figures dark purple shading shows locations where GI differences of $T$. ostriniae are greatest, lighter purple shows locations where differences are less pronounced; yellow shading shows locations where ACB/ECB GI is greater than T. ostriniae and white shading shows locations where $\mathrm{ACB} / \mathrm{ECB}$ GI is equal to T. ostriniae GI.

This article is protected by copyright. All rights reserved. 
Assessing the current and future biological control potential of Trichogramma ostriniae on its hosts Ostrinia furnacalis and Ostrinia nubilalis Li-Hsin $\mathrm{Wu}^{*}$, Matthew P. Hill, Linda J. Thomson and Ary A. Hoffmann ${ }^{\mathrm{a}}$ Our study is proved useful for assessing environmental factors linked to Trichogramma and its lepidopteran hosts and identifying areas suitable for inundative releases under climate change scenarios.

This article is protected by copyright. All rights reserved. 


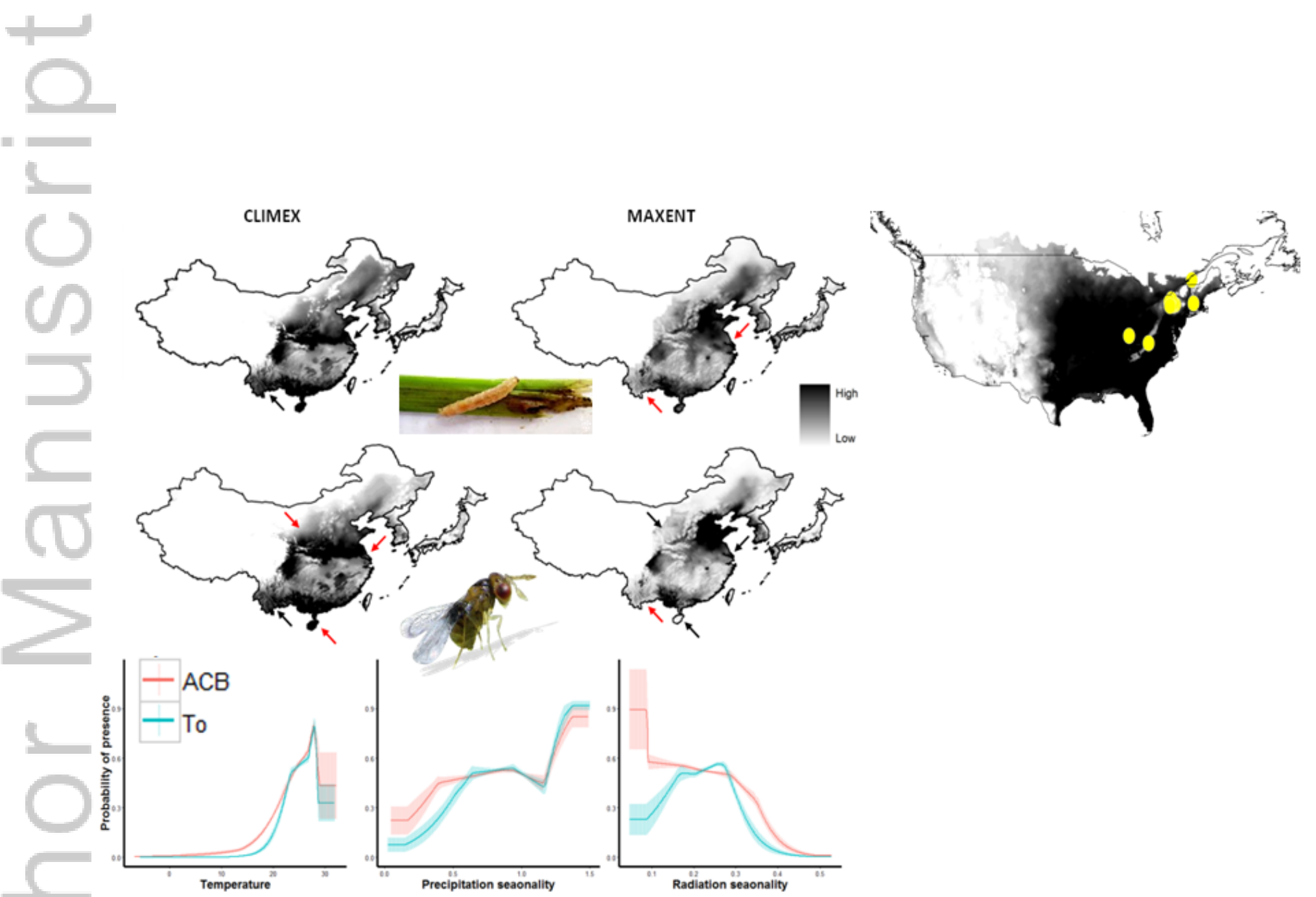

PS_4841_Graphical figure_only.tif

This article is protected by copyright. All rights reserved. 


\section{University Library}

\section{- M M N E R VA A gateway to Melbourne's research publications}

Minerva Access is the Institutional Repository of The University of Melbourne

Author/s:

Wu, L-H;Hill, MP;Thomson, LJ;Hoffmann, AA

Title:

Assessing the current and future biological control potential of Trichogramma ostriniae on its hosts Ostrinia furnacalis and Ostrinia nubilalis

Date:

2018-06-01

\section{Citation:}

Wu, L. -H., Hill, M. P., Thomson, L. J. \& Hoffmann, A. A. (2018). Assessing the current and future biological control potential of Trichogramma ostriniae on its hosts Ostrinia furnacalis and Ostrinia nubilalis. PEST MANAGEMENT SCIENCE, 74 (6), pp.1513-1523. https:// doi.org/10.1002/ps.4841.

Persistent Link:

http://hdl.handle.net/11343/283464 